\title{
El baño andalusí del Nogal o Bañuelo (ḥammām al-ŶYawza) en Granada: análisis crítico de un siglo de restauraciones (1919-2018)
}

\author{
The Andalusí bath of el Nogal or Bañuelo (hammām al-Ŷrawza) in Granada: \\ critical analysis of one century of restorations (1919-2018)
}

Antonio Orihuela $^{(*)}$, José Manuel López-Osorio ${ }^{(* *)}$

\section{RESUMEN}

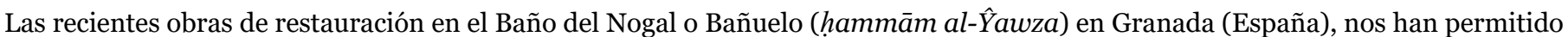
profundizar en el conocimiento de este importante ejemplo de arquitectura andalusí. En este trabajo presentamos una introducción al análisis histórico del edificio, lo que permite conocer su origen y evolución. Analizamos críticamente la docena de intervenciones de restauración y conservación realizadas durante el último siglo. Finalmente, establecemos unas conclusiones en función de las diferentes áreas del edificio, donde consideramos necesario profundizar y reflexionar, planteando propuestas que puedan ser tenidas en cuenta en la programación de futuras intervenciones. De esta forma se podrá mejorar la interpretación de un monumento singular, conservado según los criterios de la restauración científica e incorporado al patrimonio arquitectónico de la ciudad de Granada.

Palabras clave: Hammām al-ŶYawza; Bañuelo; Baño del Nogal; Baño andalusí; Granada; Conservación; Restauración de Monumentos.

\section{ABSTRACT}

The recent restoration works in the bath of El Nogal or Bañuelo (hammām al-Ŷawza) in Granada (Spain), have allowed us to deepen our knowledge of this important example of Andalusi architecture. In this paper we present an introduction to the historical analysis of the building, which allows knowing its origin and evolution. We analyze, in a critical sense, the dozen of restoration and conservation interventions carried out during the last century. Finally, we establish conclusions according to the different areas of the building, where we deem it necessary to deepen and reflect on action proposals that could be considered when programming future interventions. In this way, it will be possible to improve the interpretation of a monument, preserved according to the criteria of scientific restoration and incorporated into the architectural heritage of the city of Granada.

Keywords: Hammām al-ŶYawza; Bañuelo; El Nogal bath; Arab Bath; Granada; Conservation; Restauration of Monuments.

(*) Dr. Arquitecto, Escuela de Estudios Árabes, CSIC, Granada, Spain

$\left.{ }^{* *}\right)$ Dr. Arquitecto, Universidad de Málaga, Spain

Persona de contacto/Corresponding author: orihuela@eea.csic.es (A. Orihuela)

ORCID: https://orcid.org/oooo-0oo3-2443-552X (A. Orihuela); https://orcid.org/oooo-00o2-9545-0711 (J.M. López-Osorio).

Cómo citar este artículo/Citation: Antonio Orihuela, José Manuel López-Osorio (2021). El baño andalusí del Nogal o Bañuelo (hammām al-Ŷawza) en Granada: análisis crítico de un siglo de restauraciones (1919-2018). Informes de la Construcción, 73(562): e388. https://doi.org/10.3989/ic.78545

Copyright: (C) 2021 CSIC. Este es un artículo de acceso abierto distribuido bajo los términos de la licencia de uso y distribución Creative Commons Reconocimiento 4.o Internacional (CC BY 4.0). 


\section{INTRODUCCIÓN}

La protección del Baño del Nogal o Bañuelo a partir de su declaración como Monumento Nacional en el año 1918 coincide con las primeras planimetrías detalladas del edificio que sirvieron de base al primer Proyecto de reparación, redactado en 1927 por Leopoldo Torres Balbás, arquitecto-director de la Alhambra. El edificio, situado en el barrio del Albaicín de Granada, en la margen derecha del río Darro, es uno de los baños andalusíes mejor conservados. Ocupa una parcela rectangular de unos 12,60 x 34,45 m, con entrada por el sur, a través de una construcción de dos plantas que da a un patio desde el que se accede a las salas del baño: vestuario, sala fría, sala templada y sala caliente. Junto a ésta, en el extremo norte del conjunto, se sitúa la caldera y la sala de servicio o leñera, que debía de tener conexión con la calle para el suministro de combustibles. El baño está construido con muros de hormigón de cal y bóvedas de ladrillo con lucernas para la iluminación y el control del vapor. El agua entraba por el sector norte, a partir de un ramal de la acequia de Axares, y evacuaba por una atarjea al río Darro.

\section{FUENTES DOCUMENTALES E INVESTIGACIÓN HISTÓRICA}

No se conocen fuentes andalusíes con información del edificio, situado junto a la Puerta de los Tableros (Bāb al-Difã $f$ ), que enlazaba la estructura defensiva con la Alhambra de Granada. Su nombre, Baño del Nogal (Hammām al-Ŷawza), aparece en un documento castellano de 1494. Después pasó a denominarse baño de Palacios o de la Puerta de Guadix (1) y, posiblemente, seguiría cumpliendo su función en época morisca hasta 1567 (2). Existe documentación de una reparación realizada en 1509, cuando el carpintero mudéjar aragonés Sebastián de Palacios regentaba el Bañuelo, que necesitaba arreglos. Para ello contrató a Juan de Rojas y a Francisco de Valencia, albañiles de la ciudad, para solar la sala templada con ladrillo mazarí con grosor de tres dedos (3).

El interés de los investigadores y las fuentes documentales más abundantes se producen en el siglo XIX, con descripciones del edificio, grabados y planimetrías. Un análisis historiográfico detallado se encuentra en una reciente publicación de los autores del presente trabajo (4). A continuación, realizamos un resumen del mismo (Figura 1). La primera representación del Bañuelo corresponde al artista francés Girault de Prangey en 1837 (5), que dibujó una planta y una vista de la sala templada convertida en lavadero público, uso que mantendría hasta mediados del siglo XIX (6). En el año 1878, Rafael Contreras, restaurador de la Alhambra, publicó una nueva planta y un grabado de la sala templada (7), inspirados en los de Girault de Prangey, aunque con mayor precisión en la hipótesis del trazado simétrico del actual patio de entrada. Los investigadores granadinos Gómez-Moreno González y su hijo Gómez-Moreno Martínez fueron los primeros en describir sus elementos arquitectónicos con precisión arqueológica. El segundo publicó una reseña de la visita realizada en 1889 por el Centro Artístico de Granada (8), haciendo referencia a los arcos y capiteles de la sala templada. Tres años después, en su Guía de Granada (9), el padre hizo una completa descripción del baño. En la sala templada precisó que sus columnas eran reaprovechadas de edificios anteriores, resaltando también los tres arcos fingidos pintados en su pared norte. Indicó el uso como horno y leñera en las estancias septentrionales, donde había escombros, y vio el arranque de la desaparecida "bóveda arqueada" de la leñera. Por la antigüedad de sus caracteres arquitectónicos lo dató en el siglo XI, lo que ha prevalecido en la historiografía hasta época reciente.

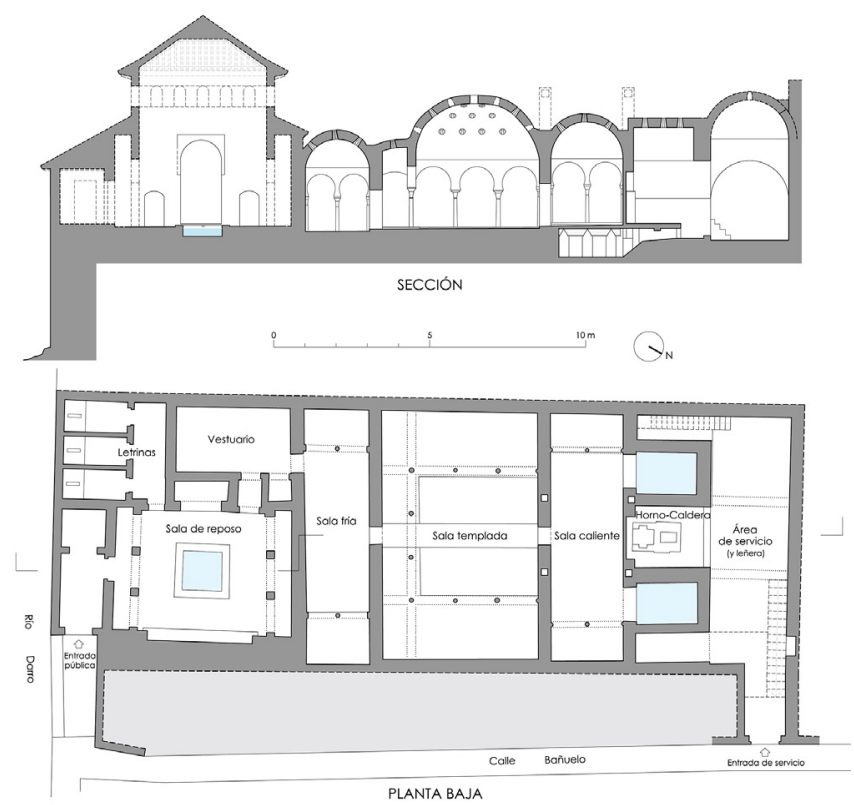

Figura 1. Planta y sección hipotéticas del Bañuelo, según Orihuela y López-Osorio, incluyendo las aportaciones de Almagro (2014)

La primera noticia sobre trabajos para recuperar la estructura original del baño corresponde a 1912. Su propietario Enríquez de Luna (10) solicitó licencia municipal para desescombrarlo, pues un relleno de más de un metro cubría la mitad de las columnas (11) cuando la sala templada era un lavadero público. En 1919, el arquitecto Wilhelmi y Manzano realizó un plano de la planta baja (APAG P-o01155), dibujando la vivienda de la entrada y un aljibe contemporáneo que ocupaba el tercio oriental de la sala fría. En 1927, Torres Balbás, redactó el Proyecto de reparación del Bañuelo. En abril de 1928 hizo una reseña en la Revista Reflejos: "Adquirido con cargo a los ingresos por entradas en la Alhambra, el Bañuelo, interesante baño árabe del siglo XI, situado en la Carrera del Darro, al finalizar el mes de Marzo se terminó su reparación, salvado definitivamente de una destrucción que parecía casi segura” (12).

En 1951, Gómez-Moreno Martínez realiza otra descripción detallada del Bañuelo, aportando planos de planta y sección (13) basados en la planimetría que Torres Balbás había levantado durante las obras de 1927-28 (APAG P-000269 y P-000271).

En el siglo XXI, el Bañuelo vuelve a interesar a los investigadores. En 2012, Navarro Palazón y Jiménez Castillo, analizan el baño y su entorno urbanístico, planteando la entrada desde la Carrera del Darro por la esquina suroeste del edificio. Sugieren, además, que habría una sala de reposo-vestuario cubierta con linterna y armadura de madera en el actual patio de ingreso. Lo datan en el siglo XII por sus características constructivas (14). Posteriormente, Almagro Gorbea, incide en demostrar lo que había sugerido diez años antes, coincidiendo con Navarro y Jiménez: que el actual patio de acceso era una sala cubierta con linterna (15), publicando planimetrías del estado actual e hipotético inicial, y anotando que "la tipología del baño, que consideramos muy evolucionada y similar a los de época nazarí, permitiría pensar en una fecha mucho más 
avanzada" (16). Estos trabajos han hecho replantearse a algunos autores las cronologías tradicionales (17).

\section{PROYECTOS DE RESTAURACIÓN}

A continuación, analizamos los proyectos y obras de restauración realizados en el Bañuelo desde las primeras décadas del siglo XX hasta nuestros días.

1927. Leopoldo Torres Balbás. Proyecto de reparación del Bañuelo, Granada. Diciembre de 1927. Importe: 17.013 Pts. Ministerio de Instrucción Pública y Bellas Artes (APAG, Leg. 2005/004)

Con carácter previo se realizaron trabajos de exploración y limpieza que sirvieron para definir las actuaciones incluidas en la Memoria y que recogemos según la estructura original del documento:

a. Desescombro de habitaciones de servicio y retirada de tierra de salas y riñones de bóvedas.

b. Derribo de construcciones modernas sobre las bóvedas, dejando solo la nave de fachada a la Carrera del Darro, donde se instalará la vivienda del guardián; exploración del subsuelo de esa casa y patio de entrada para buscar cimientos antiguos.

c. Reconstrucción de la antigua atarjea general existente junto al lindero oeste; pavimentación con ladrillo mazarí de las salas abovedadas excepto la templada que se hará con mármol blanco según vestigios descubiertos, dejando la solería a la altura primitiva.

d. Reconstrucción de lucernas en su antigua forma, trasdosándolas con mortero de cemento, fratasándolas e impermeabilizándolas con alquitrán (Figuras 2-3); colocación de vidrios en las lucernas y bajantes de hierro en cajas hechas en los muros para desaguar las bóvedas en atarjea general.

e. Reconstrucción de bóvedas de los pequeños aposentos de la cámara del fondo donde pudo haber pilas de agua y la del local de la caldera, las primeras serán por arista, según vestigios, y la última de cañón según se acusa claramente; estas bóvedas han de reconstruirse, pues sino entraría el agua de lluvia al resto de locales. La del aposento del fondo en cambio, que también fue de cañón, no se consideraba urgente reconstruirla.

f. Derribo del muro de la estancia más próxima a la entrada, mediando con la nave moderna de fachada, pues por su insuficiente cimentación y pasar bajo él la atarjea, está muy volcado y es necesario reconstruirlo aplomado (Figura 4). También será necesario derribar y reconstruir el muro inmediato de la nave, que se halla falto de cimentación y en mal estado.

g. Construcción de la escalera de ladrillo a la catalana para subir a las bóvedas y piso alto de la vivienda del guardián, pues había sido derribada la escalera moderna situada en el patio de entrada.

La inexistencia o pérdida del "Diario de Obras" del Bañuelo, con el que Torres Balbás documentaba sus trabajos, impide conocer la descripción minuciosa de éstos, así como de los datos arqueológicos que aparecieron. Sobre esta actuación solo publicó un párrafo poco después, donde indicaba que "fue obra de 1927 a 1928, derribando construcciones parásitas y haciendo una labor de saneamiento y consolidación, sin privarle de su sugestivo aspecto de vejez" (18). Esta frase contiene las ideas que guiaban sus actuaciones, realizadas

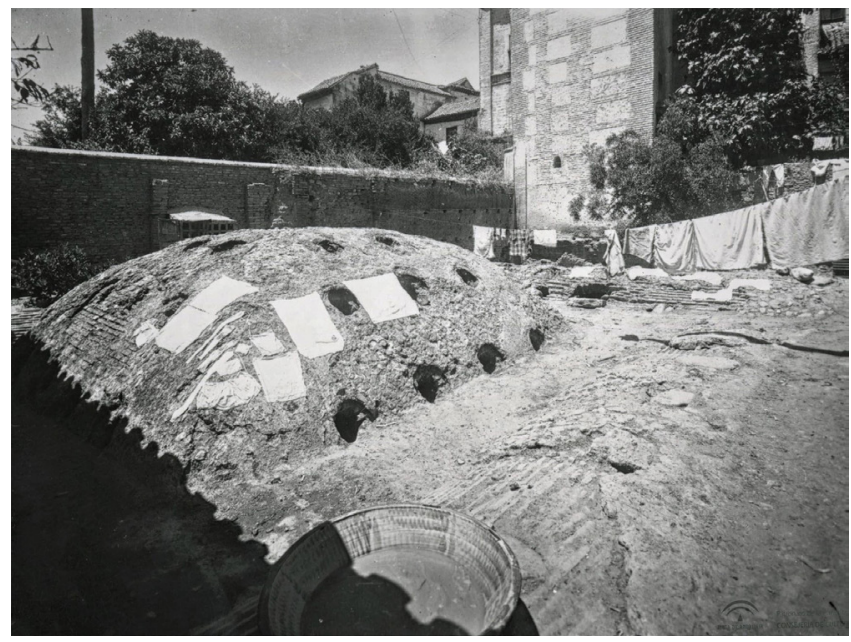

Figura 2. Extradós de las bóvedas del Bañuelo antes de la obra de intervención de Torres Balbás (APAG F-003262).

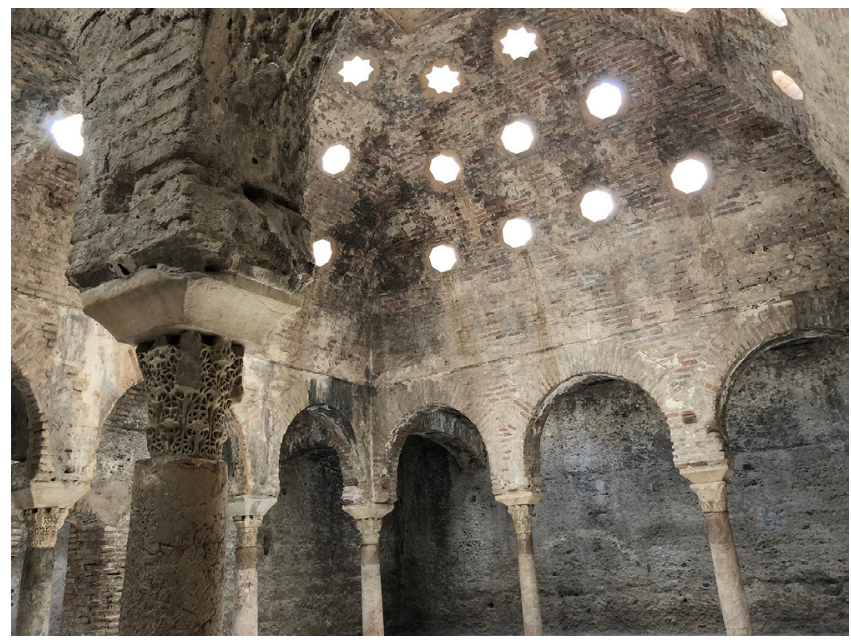

Figura 3. Intradós de la bóveda y arcos de la sala templada del Bañuelo. En primer plano detalle de columna, capitel y cimacio.

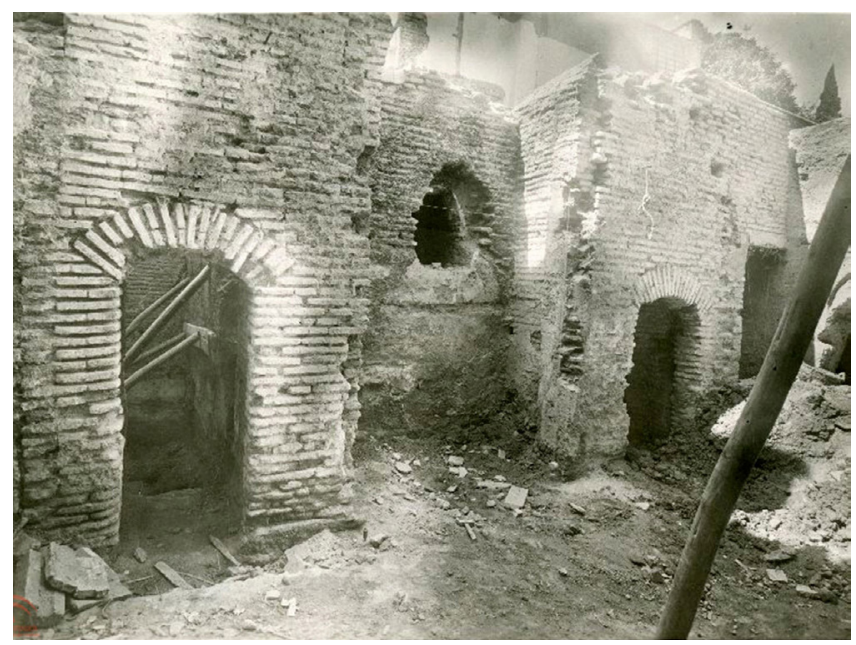

Figura 4. Patio de acceso al Bañuelo durante la ejecución de las

obras de Torres Balbás en 1927-28 (APAG F-007288).

con economía de medios y mínimas intervenciones, evitando introducir elementos superfluos, y ejecutadas con sensibilidad, para no privar al edificio de su aspecto de obra medieval. La actuación mantuvo pátinas en bóvedas y paramentos, lo que ha permitido su lectura arqueológica hasta nuestros días. 
La exploración del subsuelo aparece en el plano hecho durante las obras (Figura 5), donde se aprecia la atarjea general junto a la medianería oeste, hasta evacuar al río Darro. En su recorrido, desde la sala de servicio, recibía dos conexiones: de la pileta oeste de la sala caliente y de la alberquilla del patio de entrada. Durante las obras debieron de conectarse también las dos bajantes de la cubierta, situadas en las esquinas de la alhanía oeste de la sala fría. Un registro arqueológico relevante se dibuja en la nave de la Carrera del Darro, donde apareció un muro de hormigón de casi $4 \mathrm{~m}$ de longitud y $60 \mathrm{~cm}$ de espesor, paralelo al muro de fachada y alineado con el de la vivienda de la entrada al Bañuelo. Dicho muro fue localizado, de nuevo, en la excavación realizada por los arqueólogos José Álvarez y Ana Palanco en 2014, como apoyo a las obras de adecuación al nuevo uso turístico. El muro es simétrico respecto al eje este-oeste del patio, en relación al que lo cierra por el norte, pues ambos limitarían la gran sala de reposo original, lo que corrobora la hipótesis de Almagro (19) con galerías en los frentes norte y sur.

Restos de la galería sur pueden verse también en el plano, donde se dibuja el arranque de un machón de ladrillo. Una planta similar había sido ya intuida por Girault de Prangey (20). En las anotaciones al plano de Torres Balbás puede leerse, además, que este muro de hormigón estaba "roto" en su extremo este, lo que podría dar continuidad al espacio por este sector. No debería descartarse la existencia de una tercera galería u otras dependencias en este ámbito, donde ahora está la vivienda de la calle Bañuelo, $n^{0} 3$. Esta posibilidad estaría relacionada con la cronología del primer nivel del actual muro de fachada de la Carrera del Darro y que Almagro considera original, dibujando una sola altura con letrinas en su extremo occidental. La hipótesis parece razonable, pues éstas se dispondrían ventiladas sobre la atarjea general. Tampoco debemos descartar que la construcción de la fachada actual se hiciera con la apertura de este tramo de la calle, a principios del siglo XVII, cuando se acondicionó la Carrera de la Puerta de Guadix, actual Paseo del Padre Manjón (21).
En el plano se dibujaron también restos de pavimentos de ladrillo en el actual patio y otros en la sala caliente, además de nueve vestigios de solería de mármol blanco en la sala templada, que permitieron rehacer el canal rehundido que cruza la estancia (Figura 6). Aunque en el apartado c) de la Memoria no se decía nada sobre la pavimentación del patio, en contraste con los restos de ladrillo subsistentes se realizó un nuevo pavimento de empedrado artístico con guijarros blancos y negros.

Afortunadamente, durante la obra no se colocaron las bajantes de cubierta en cajas hechas en los muros, instalándose en las esquinas de la alhanía occidental de la sala fría. La conexión con la atarjea se hizo mediante conducciones independientes bajo el pavimento, que fueron identificadas en las obras de 2005-06. En estos trabajos se localizaron también restos de mortero de cemento que, como revestimiento, se habían aplicado en 1927-28 en las paredes de la atarjea. Respecto a la reconstrucción de las bóvedas en la zona norte, además de las tres previstas en el apartado e), se hizo otra de medio cañón en el espacio situado al oeste de aquellas, donde se conservaban los peldaños de una escalera de ladrillo que permitiría subir a las cubiertas desde la leñera. En el paramento del muro de hormigón de este sector encontramos improntas del replanteo del arco de la bóveda de esta escalera. Torres Balbás no alude a ella en el proyecto, aunque dibuja su arranque en los croquis (APAG P-008677) y planos de obra (Figura 5).

La escalera a la que se refiere el apartado g) la sitúa en el otro extremo del baño, junto a la vivienda, que se construye y cubre con una terraza. Durante las obras debieron de repararse los muros medianeros de la sala de servicio tras el desescombro del sector, pues aun aparecen en los paramentos lagunas de ladrillo, probablemente asociadas a esta intervención. También reconstruyó los arcos situados bajo la desaparecida bóveda de cañón, como se refleja en los planos del proyecto, pues hacían falta para mantener estable el conjunto al decidir no rehacer la bóveda, según dice la Memoria. Estos arcos y la rosca de ladrillo, conservan todavía los arranques medievales, que fueron identificados por Gómez-Moreno al referirse a la desaparecida "bóveda arqueada" de la leñera (1).

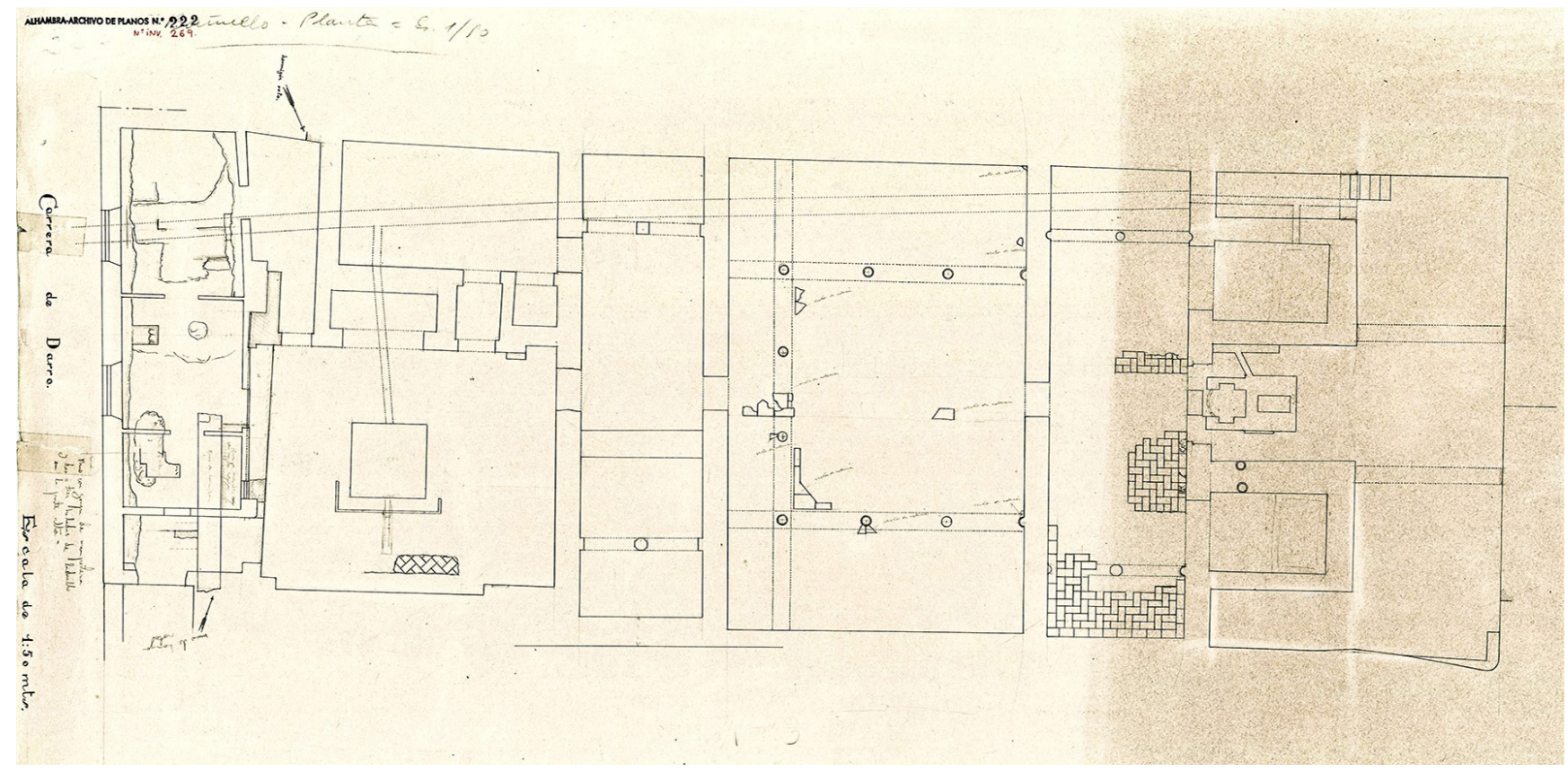

Figura 5. Plano de Torres Balbás, de diciembre de 1927, con el registro arqueológico realizado durante las obras (APAG P-000269). 


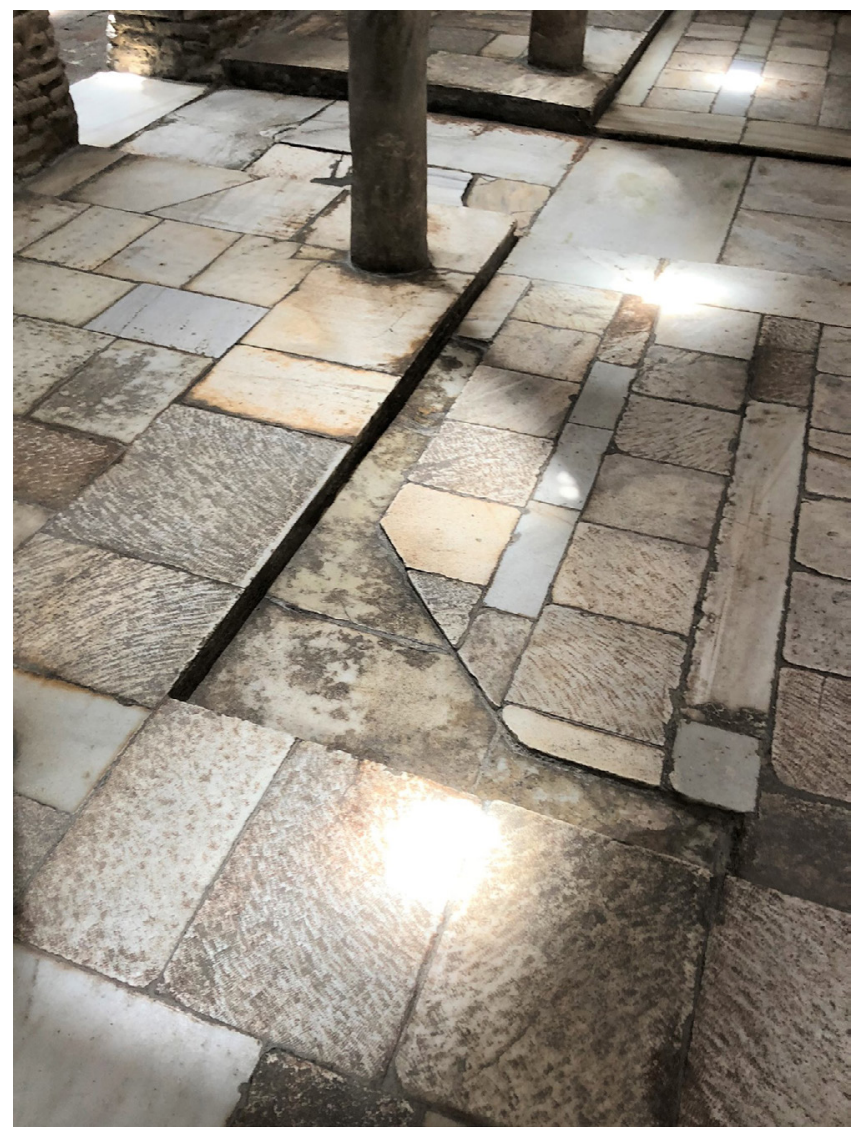

Figura 6. Pavimento de la sala templada con restos antiguos de mármol blanco integrados con los nuevos de las obras de 1927-28.

1932. Leopoldo Torres Balbás. Arreglo de muro medianero en el Bañuelo, Granada. Noviembre de 1932. Importe: 3.00o Pts. Ministerio de Instrucción Pública y Bellas Artes (APAG, Leg. 2005/004).

El muro de la casa de la calle Bañuelo $\mathrm{n}^{\mathrm{o}} 3$, medianero con el actual patio de entrada, había quedado sin tratar en las obras de 1927-28, después de demoler la crujía de viviendas que lo cubría, tal y como se aprecia en las fotografías (APAG F-007284) (Figura 7). Ante las protestas de la propiedad colindante, el Ministerio, a petición de Torres Balbás, concedió un presupuesto para ejecutar dichas obras.

1955. Francisco Prieto-Moreno Pardo. Obras de reparación en los baños árabes del Bañuelo, Granada. Abril de 1955. Importe: 10.00o Pts. Conservación de Monumentos de la $7^{\mathrm{a}}$ Zona (AGA, caja 71.090).

Aunque en el Archivo General de la Administración existen expedientes anteriores, de 1942 y 1952, nos referiremos aquí al proyecto de 1955. En la Memoria se indica su principal objetivo: "El trasdós de estás bóvedas se encuentra a la intemperie sufriendo los efectos de las frecuentes heladas que en invierno se dan en Granada, desconchando la capa de lechada de cemento que tienen como impermeabilizante. Se producen grietas a través de la cuales recala el agua de lluvia al interior humedeciendo la fábrica de bóvedas y pilares con el consiguiente daño".

También propone "recalzar por puntos" los daños ocasionados por una higuera en el muro medianero con la edificación colindante en la antigua leñera, cuyas raíces han permaneci-

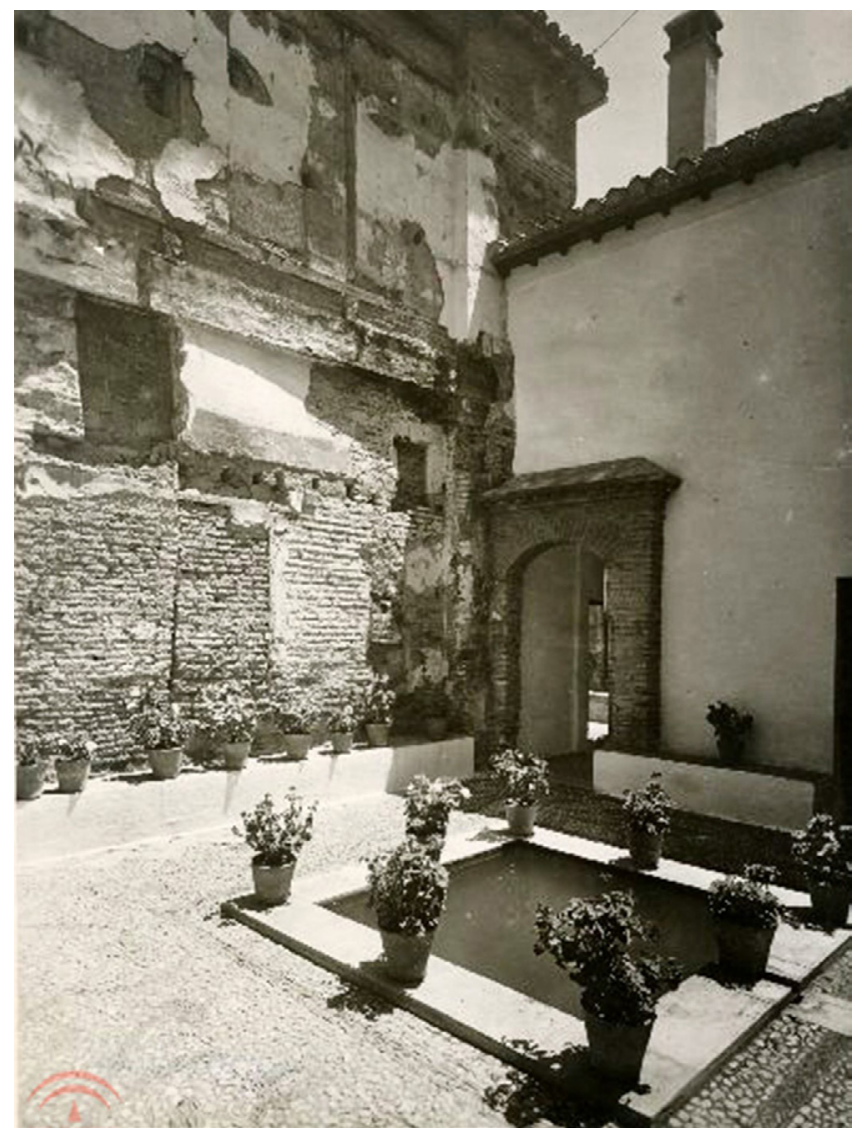

Figura 7. Medianería sin tratar en la vivienda del patio de acceso, una vez finalizadas las obras en 1927-28 (APAG F-007284).

do en los muros hasta las actuaciones de 2015-18. No incluye planos ni presupuesto, sólo tres fotografías del exterior de las bóvedas en las que aparecen abundantes fisuras, que presentan el estado tras los trabajos de Torres Balbás y donde se ven sólo dos chimeneas de salida de humos, que parecen cegadas. No sabemos si la impermeabilización de la cubierta se realizó, aunque puede que se limitara a una pintura asfáltica. Los trabajos de recalce del muro medianero sí debieron de ejecutarse, ya que aún existen parches de ladrillo en el mismo, que podrían relacionarse con esta actuación.

1972. Francisco Prieto-Moreno Pardo. Obras de restauración en el Bañuelo, Granada. Abril de 1972. Importe: 99.435 Pts. Ministerio de Educación y Ciencia (AGA, caja 70.675).

La Memoria indica que las bóvedas precisan "periódicamente efectuar una labor de rejuntado de los sillares (sic) y reparación de lucernas de cristal". También comprende el saneamiento de las partes bajas de muros para impermeabilizarlos por el exterior con revestimientos de mortero de cemento, así como la reparación del pavimento de losas de barro cocido y de los escalones de ladrillo. En la vivienda del guarda se propone reparar las cubiertas, bajantes de pluviales y carpinterías. El proyecto contiene cuatro fotografías: exterior de las bóvedas desde el sur, extremo este de la sala caliente, cuadrante suroeste de la sala templada y espacio de la pila de agua este en la sala caliente.

La intervención fue importante, con un presupuesto superior al de 1955, incluyendo la impermeabilización de cubiertas con chapa de plomo en juntas. No obstante, es posible 
que no se realizara porque el proyecto de 1975 contiene fotografías con importantes deterioros que, en realidad, fueron tomadas en 1972, aunque con distinto encuadre. Resulta difícil identificar los $62 \mathrm{~m}^{2}$ de revestido y enlucidos de mortero de cemento y los $160 \mathrm{~m}^{2}$ de entresacado de pavimentos de barro cocido.

1975. Francisco Prieto-Moreno Pardo. Obras de restauración en el Bañuelo, Granada. Junio de 1975. Importe: 247.761 Pts. Ministerio de Educación y Ciencia (AGA, caja 70.780).

La Memoria dice que "se trata de efectuar una corrección de humedades, reparación de paramentos, impermeabilización de bóvedas y reparación de pavimentos", evitando las humedades en las bóvedas mediante una capa asfáltica y un tendido de mortero bastardo de cal y cemento. También dice que se repondrán piezas en los pavimentos de losas de barro, incluyendo una partida de ladrillo macizo asentado con mortero de cemento. Así mismo, se picarán los revocos afectados por humedades, incluso las juntas de fábrica de ladrillo que serán tratadas con mortero bastardo.

El proyecto contiene cuatro fotografías: fachada a Carrera del Darro, Patio Posterior [sala de servicio], Sala segunda [sala fría] y Exterior de las bóvedas (Figura 8). En la imagen de la sala fría falta uno de los cimacios de la arcada de la alhanía oeste, que no había sido repuesto por Torres Balbás y que sí se instaló en la intervención de 1994-96, así como el estado de las bajantes colocadas entonces y que fueron sustituidas posteriormente por atanores cerámicos. En la fotografía de las bóvedas pueden verse las lucernas después de la actuación de Torres Balbás, así como la edificación de la vivienda donde aparece el volumen aterrazado de las escaleras, todo ello antes de la galería añadida en 1983 .

Por primera vez, el proyecto incorpora un plano de planta y una sección, que es copia de la incluida por Torres Balbás en su proyecto de 1927, sobre la que se dibuja vegetación en el patio de entrada y zona de servicio. La planta recoge la atarjea del baño y en la sección se representa el hipocausto, aunque de forma incorrecta, ya que el plano original tenía un error. Torres Balbás corregiría posteriormente la representación de este espacio, tal y como aparece en la sección dibujada durante las obras (APAG P-000271).

La descripción de los trabajos de este proyecto coincide con el de 1972, aunque el presupuesto es superior. Si analizamos las fotografías de las bóvedas y del interior, vemos como el estado es similar a 1972. El tendido de mortero bastardo parece que no se ejecutó, aunque es posible que se realizara la impermeabilización, de la que quedaban restos en 2006. También debieron de hacerse los "llagueados en tendeles de fábrica de ladrillo" y los revestimientos de paramentos verticales. Sin embargo, no parece que se ejecutara la pintura a la cal en el interior, sino en los paramentos exteriores de la Carrera del Darro.

1981-1983. Carlos Sánchez Gómez. Proyecto de restauración en el Bañuelo, Granada. Abril de 1981. Importe PEM: 711.875 Pts. Ministerio de Cultura (AGA, caja 94.666).

Hubo una actuación previa denominada Obras de Emergencia en el Bañuelo de Granada, con un presupuesto de

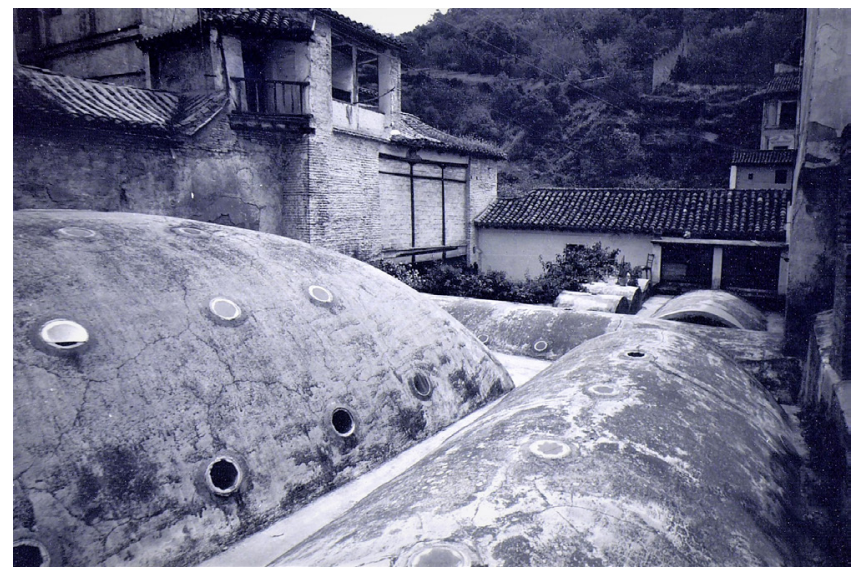

Figura 8. Bóvedas del Bañuelo antes de las obras de 1975 de Prieto-Moreno. Al fondo, volumen de la vivienda (AGA, 26/0oo96).

60.00o Pts, demoliendo un falso techo en la vivienda del conserje e instalando mecanismos de electricidad. La obra general fue ejecutada en julio de 1983, según proyecto redactado en 1981, y consistía en una actuación parcial en la crujía de la Carrera del Darro, donde la vivienda aún mantenía las instalaciones higiénicas de 1928 con tres dormitorios en planta alta sin acceso independiente. La solución fue crear una galería cerrada orientada al patio para conectarlos, aprovechando su extremo este para hacer un cuarto de baño. Se repararon los tejados, ampliando el faldón interior de teja para recoger la galería.

El nuevo cuerpo de edificación se construyó sobre pilastras de ladrillo coronadas por zapatas de hormigón, que soportan la viga de madera del pórtico. El cerramiento de la galería se

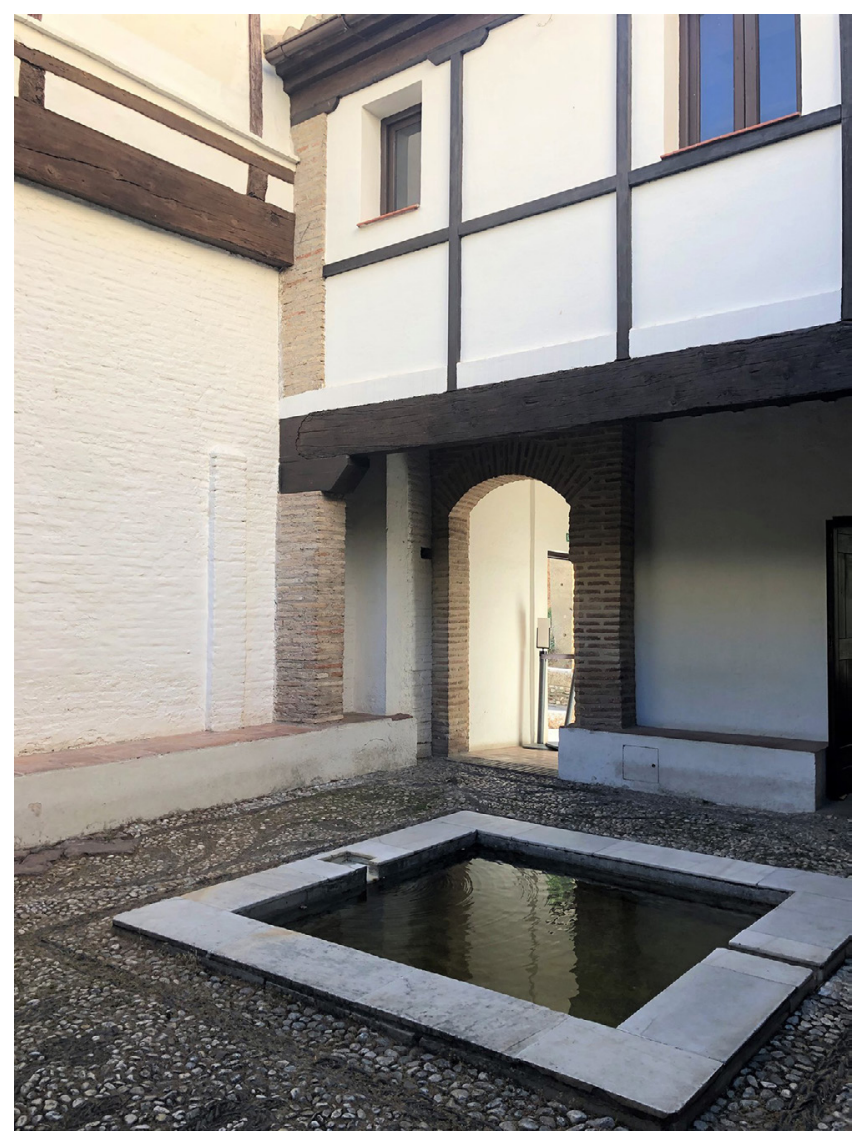

Figura 9. Patio de entrada al Bañuelo con la actual galería añadida. 
hizo con fábrica capuchina, presentándose exteriormente con pies derechos de madera con zapatas sencillas y escuadrías horizontales sobre el que aparecen dos ventanas (Figura 9), solución que pretendía mimetizar con la de la medianera este del patio. Los trabajos mejoraron la habitabilidad de la vivienda, pero la formalización y ampliación del volumen dificultan la comprensión del espacio, que fue la sala de reposo del baño antes de convertirse en patio abierto. El lenguaje historicista descontextualizado, tomado de la medianería colindante, altera el carácter del espacio original y refuerza un ambiente simulado de patio de vivienda tradicional, ajeno a la historia del edificio.

1991-92. Ignacio Gárate Rojas. Proyecto de restauración de las fachadas de la Carrera del Darro. Consejería de Cultura, Junta de Andalucía.

Se trataba de un proyecto global de rehabilitación de fachadas en la Carrera del Darro que supuso una importante labor de recuperación de las pinturas murales existentes, obteniendo el Premio Europa Nostra 1992. En el Bañuelo la actuación se limitó a la aplicación de un revestimiento de mortero de cal en su fachada exterior y un zócalo rosado con textura rugosa de dudosa relación con aquel. Estos revestimientos han sido eliminados en la mayoría de las fachadas del Darro, debido a su deficiente conservación como consecuencia del mal comportamiento de la cal utilizada, pues comenzaron a disgregarse y desprenderse a los pocos años. Los del Bañuelo fueron quitados en 2005-06.

1989-95. Rafael Rodríguez Sáez. Restauración de los Baños Árabes del Bañuelo, Granada. Febrero 1993. Importe PEM: 4.816.659 Pts. Consejería de Cultura, Junta de Andalucía (BC. 01161/94).

Aunque el proyecto incluía también otras actuaciones, como la iluminación interior del baño, las obras realizadas en 199495 fueron:

- Renovación del aseo de visitantes.

- Impermeabilización de bóvedas, instalación de sumideros y bajantes y aplicación de tratamiento superficial con slurry acrílico rojizo.

- Sustitución de vidrios en lucernas por piezas de policarbonato con aros de acero inoxidable.

- Pavimento y canal del patio de la zona de servicio, con baldosa cerámica y olambrilla verde.

- Limpieza y reparación general de pavimentos.

- Construcción de escalera de subida a las bóvedas desde la zona de servicio, con ladrillo macizo a sardinel.

- Reja metálica abatible de una hoja para cierre de la escalera, y otra abatible de dos hojas en el hueco entre la sala caliente y el horno, con diseños inspirados en motivos del artista M.C. Escher (1898-1972).

- Rejillas metálicas de acero galvanizado, como suelo de protección en el ámbito del horno y la pileta del lado oeste de la sala caliente.

- Reposición de dos columnas semiempotradas de piedra caliza gris de Sierra Elvira, bajo los extremos del doble arco de la alhanía oeste de la sala caliente y colocación de cimacios del mismo material, donde se grabó el año de ejecución: 1995.

- Reposición de cimacio en la alhanía oeste de la sala fría.

- Poda y renovación de vegetación existente, sustituyendo la hiedra del patio de acceso por parra virgen.

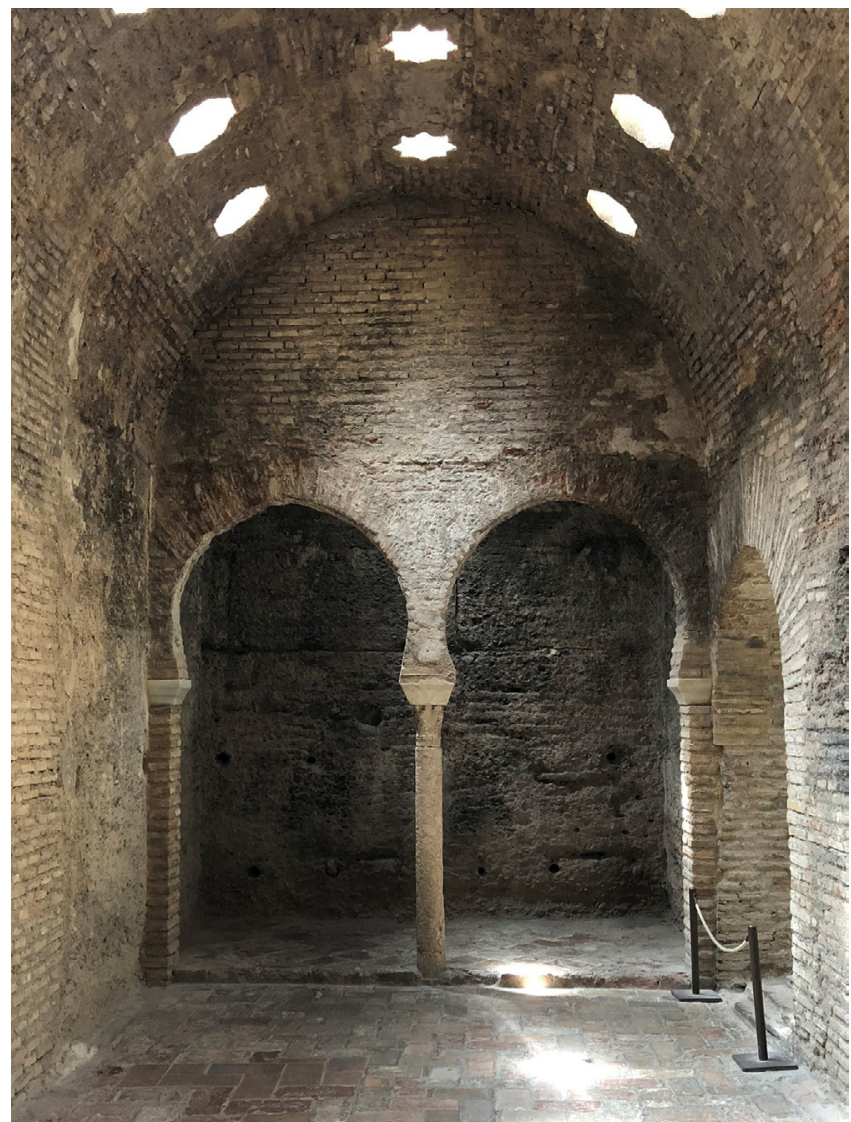

Figura 10. Alhanía oeste de la sala caliente del Bañuelo, con las actuales pilastras de ladrillo y cimacios.

Finalizados los trabajos, la Delegación de Granada de la Consejería de Cultura, promotora de las obras, realizó tres intervenciones “correctoras". Se sustituyó la reja metálica colocada en el hueco entre la sala caliente y el horno, por otra tradicional de barrotes verticales. Se retiraron columnas y cimacios de piedra de Sierra Elvira de los extremos de la alhanía oeste de dicha sala y se colocaron pilastras de ladrillo con cimacios de mármol blanco de Macael (Figura 10). Se retiró la rejilla metálica de acero galvanizado del suelo de la pileta de la sala, prohibiéndose el acceso a su interior.

Las dos primeras modificaciones merecen ser analizadas. Rodríguez Sáez, para manifestar la contemporaneidad de su actuación y siguiendo las prescripciones del Art.7. a) de la Carta del Restauro italiana de 1987, diseñó unas rejas con un motivo actual, reconocible y valorado intelectualmente. Sin embargo, la situada en la sala caliente se consideró demasiado impactante, por lo que fue eliminada, manteniéndose solo la de las escaleras de acceso a las bóvedas, por ser zona cerrada al público. Por otra parte, las nuevas columnas y cimacios de Sierra Elvira, contribuían a la estabilidad estructural sin prestarse a confusión con las columnas originales, realizadas con otro tipo de piedra, por lo que consideramos que esta intervención era adecuada, resultando injustificada la instalación de las pilastras y los nuevos cimacios. No obstante, es cierto que esta solución sí aparecía originalmente en la sala fría, y que ambas estancias presentan una estructura similar, aunque existe una jerarquización a favor de la caliente, por su mayor anchura y disponer columnas y capiteles de acarreo, en los arcos de sus alhanías. De ellas solo se conservan las del lado este, semiempotradas en los muros, mientras que las 
del opuesto habrían sido expoliadas, quedando su impronta como espacio vacío semicilíndrico.

Este detalle fue recogido en los planos de Torres Balbás (Figura 5) y mantenido como testimonio arqueológico en sus obras y en las de Prieto-Moreno. Sin embargo, la nueva actuación ocultó esta huella material al insertar las pilastras y sustituir el material de los cimacios que las coronan, alterando la valorización formal del espacio y su correcta interpretación. Cabe destacar, no obstante, que se mantuvo el registro del año de la actuación, que fue nuevamente grabado en los nuevos cimacios, siguiendo el proyecto de Rodríguez Sáez.

2005-2006. José Manuel López Osorio. Conservación y reparación de los baños árabes del Nogal o Bañuelo (Granada). Consejería de Cultura, Junta de Andalucía.

La actuación se realiza a requerimiento del Ayuntamiento de Granada para cumplimentar la Inspección Técnica de Edificios realizada en 2004. Se perseguía un doble objetivo: mejorar la imagen urbana del Bañuelo, cuya fachada estaba deteriorada, y resolver las humedades de filtraciones de cubierta y las fugas de instalaciones de pluviales y saneamiento que afectaban por capilaridad a los muros del baño. Las obras fueron las siguientes:

- Reparación de fachada exterior, eliminando el zócalo de 1992 y renovando revestimientos y rejuntados de fábricas.

- Reparación del faldón de teja e impermeabilización de la azotea de la escalera.

- Reparación de la alberca del patio, mediante renovación de canalizaciones y tratamiento de paredes interiores.

- Recuperación funcional de la atarjea, que estaba atorada y no tenía conexión con la red de alcantarillado ni salida al río, pues había sido clausurada, por error, durante las obras de remodelación de la Carrera, ejecutadas la década anterior. Para realizar estos trabajos se hicieron catas arqueológicas para localizar la atarjea de ladrillo, procediéndose a la limpieza del material acumulado y a la instalación, en su interior, de una conducción de polietileno de $\varnothing=200 \mathrm{~mm}$. En el tramo final se construyó una arqueta sifónica registrable y acometida a la red urbana.

- Reposición de pavimentos afectados por las obras de la atarjea, recolocando las piezas cerámicas en buen estado y sustituyendo las restantes por otras similares. En el patio se reparó el empedrado según diseño existente.

- En la cubierta se renovaron los sumideros, que se conectaron con las dos bajantes de atanores existentes en las esquinas en la alhanía oeste de la sala fría. Una de las bajantes se conformó con las piezas cerámicas que estaban en buen estado, mientras que en la otra se instalaron nuevas de fabricación artesanal.

- Acondicionamiento del zaguán de entrada, aseo de visitantes y vivienda del conserje, incluyendo renovación de instalaciones eléctricas y reposición de revestimientos y pavimentos.

En el extradós de la bóveda de la sala caliente, se realizó una cata hasta alcanzar la rosca de ladrillo medieval, que permitió identificar los materiales de la intervención de Torres Balbás y documentar el bloque de cemento y fragmentos cerámicos que daba forma a las lucernas. Un Informe Final de Obra documenta la actuación e incluye planos de la atarjea general y de los pavimentos reparados.
2014-15. María Cullel Muro. Intervención en las cubiertas, adecuación de accesos, y obras consolidación, protección e intervención en los edificios de la Dobla de Oro. Patronato de la Alhambra y Generalife (22).

Debido a la adscripción del Bañuelo a la gestión del Patronato de la Alhambra y Generalife, se realizaron las siguientes intervenciones para adaptarlo a la recepción y control de la visita turística:

- Limpieza de cubiertas en la antigua casa del guarda y adecuación de planta baja, mediante instalación de un aseo de personal, sala de instalaciones y elementos de equipamiento.

- Adecuación de accesos a personas con movilidad reducida mediante rampa empedrada exterior y de madera para el acceso al interior.

- Impermeabilización de bóvedas, sustituyendo el tratamiento rojizo de 1994-95, por pintura de color integrado.

- Reposición de pavimentos interiores con piezas cerámicas de diferentes formatos, con referencia dimensional según las piezas sustituidas.

- Reparación del sistema de circulación de agua en la alberca del patio, e instalaciones de electricidad, audiovisuales, protección contra incendios, sistema de seguridad con CTV (23).

2017. Servicio de Conservación y Protección. Departamento de Restauración. Obras de restauración de las pinturas murales de la Sala Templada. Patronato de la Alhambra y Generalife (24).

Los trabajos consistieron en la limpieza y consolidación de los restos de pinturas murales existentes en el muro que separa la sala templada de la caliente, que representan tres arcos de herradura con rosca de dovelas fingidas, y salmeres y enjutas decoradas con ataurique y epigrafía cúfica, con capiteles, también decorados, sobre columnas. Estas pinturas de color rojo, ya identificadas por Gómez-Moreno (1), están realizadas al fresco sobre el enlucido de cal que cubría el muro, y simulaban la cuarta galería de dicha sala. La intervención afectó también a la consolidación de los paramentos de ladrillo que cerraban las chimeneas de salida de humos del hipocausto. Uno de estos huecos, el situado al oeste de la puerta, ya aparecía exageradamente abierto en el grabado de Girault de Prangey. El otro se ve también, pero cerrado con fábrica de ladrillo (Figura 11).

Especial interés merecen estos cerramientos de ladrillo pues, probablemente, procedían de los trabajos de mantenimiento de época medieval o principio de época moderna, para deshollinar las chimeneas que estaría atascadas debido a su constante actividad. Estas fábricas cerámicas, situadas en ambos lados del muro de hormigón, fueron desmontadas parcialmente durante los siglos de abandono del baño y no fueron repuestas hasta los trabajos de Torres Balbás. El arquitecto ejecutó un nuevo cerramiento con ladrillo reutilizado recibido con mortero de cemento, según el criterio usado en las reintegraciones del resto del baño. El resultado mostraba la diferencia entre la obra de restauración y la fábrica de ladrillo antiguo, gracias al tipo del aparejo, pues predomina la disposición a tizón, así como por el color y textura del mortero de recibido, pues los ladrillos, al ser reutilizados, eran del mismo tipo antiguo. La actuación de 2017 afectó también a la fábrica de Torres Balbás, realizando un 


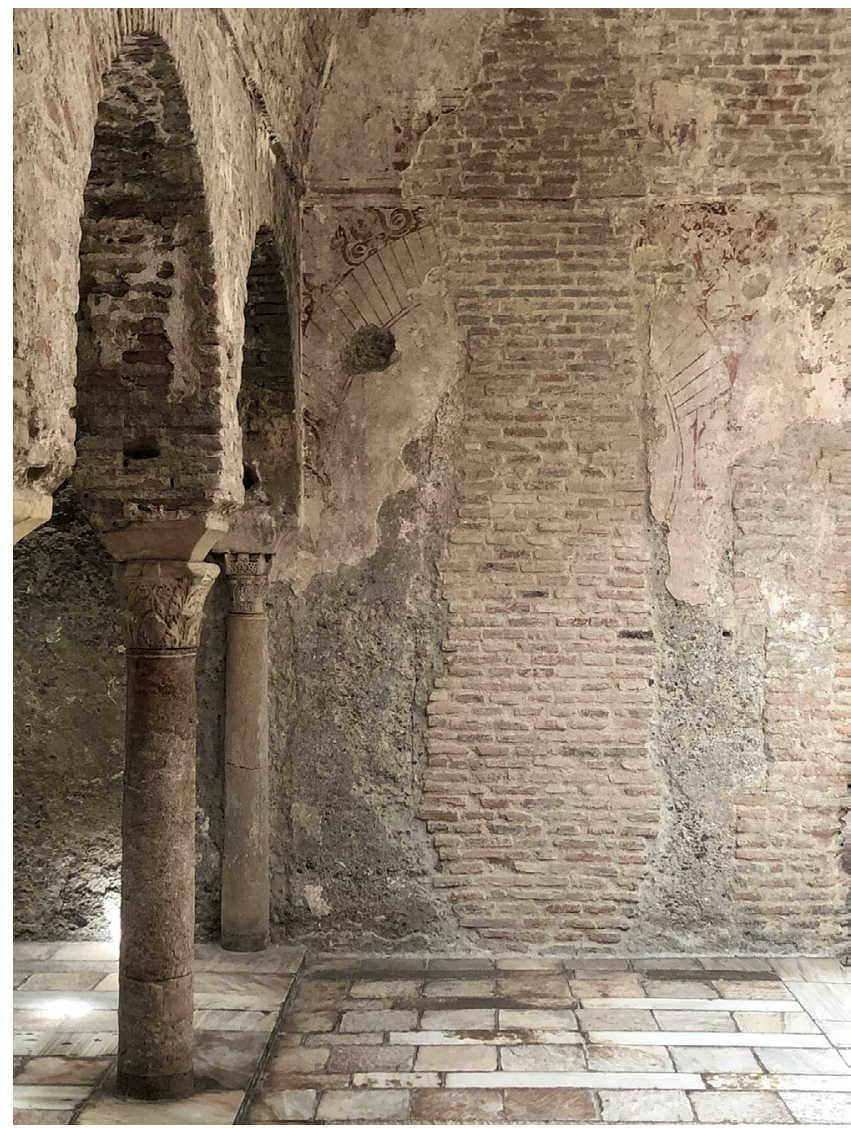

Figura 11. Vista hacia el norte de la sala templada del Bañuelo.

nuevo tratamiento epidérmico de las juntas. La solución resulta integrada pero dificulta la lectura estratigráfica presente en el paramento (Figura 11).

2015-2018. José Manuel López Osorio y Miguel Medrano Bernal. Consolidación de fábricas y paramentos de la sala de servicio del Bañuelo de Granada. Patronato de la Alhambra y Generalife.

El objetivo era abordar la degradación en los muros exteriores de la sala de servicio del baño que, al estar actualmente a la intemperie, presentaban humedades y vegetación parásita. Algunos de los paramentos afectados forman parte de los muros colindantes con los edificios vecinos y conservan recalces y reparaciones anteriores. Se hizo un levantamiento general del edificio, realizado por GECO Desarrollo Cultural S.L., un estudio histórico redactado por Ana Palanco, Teresa Koffler y Luca Mattei, y un análisis estratigráfico de estructuras emergentes y pavimentos, por Mattei. En 2015 y 2017 se redactaron sendos proyectos según las dos fases de intervención. La primera afectó a los frentes norte y oeste, y la segunda al este. Los trabajos intervienen tanto las fábricas medievales del baño como las modernas y contemporáneas, aportando una caracterización tipológica según cuatro grupos homogéneos: fábricas encofradas, mixtas, mampostería y ladrillo.

En 2017-18 se ejecutan las dos fases de la obra, llevando a cabo sendos seguimientos arqueológicos dirigidos por Mattei y Palanco. Los trabajos de restauración parten de principios de estricta conservación, con intención de manifestar las diferentes épocas históricas y su valoración relativa en el contexto del edificio. Las actuaciones consistieron en la limpieza

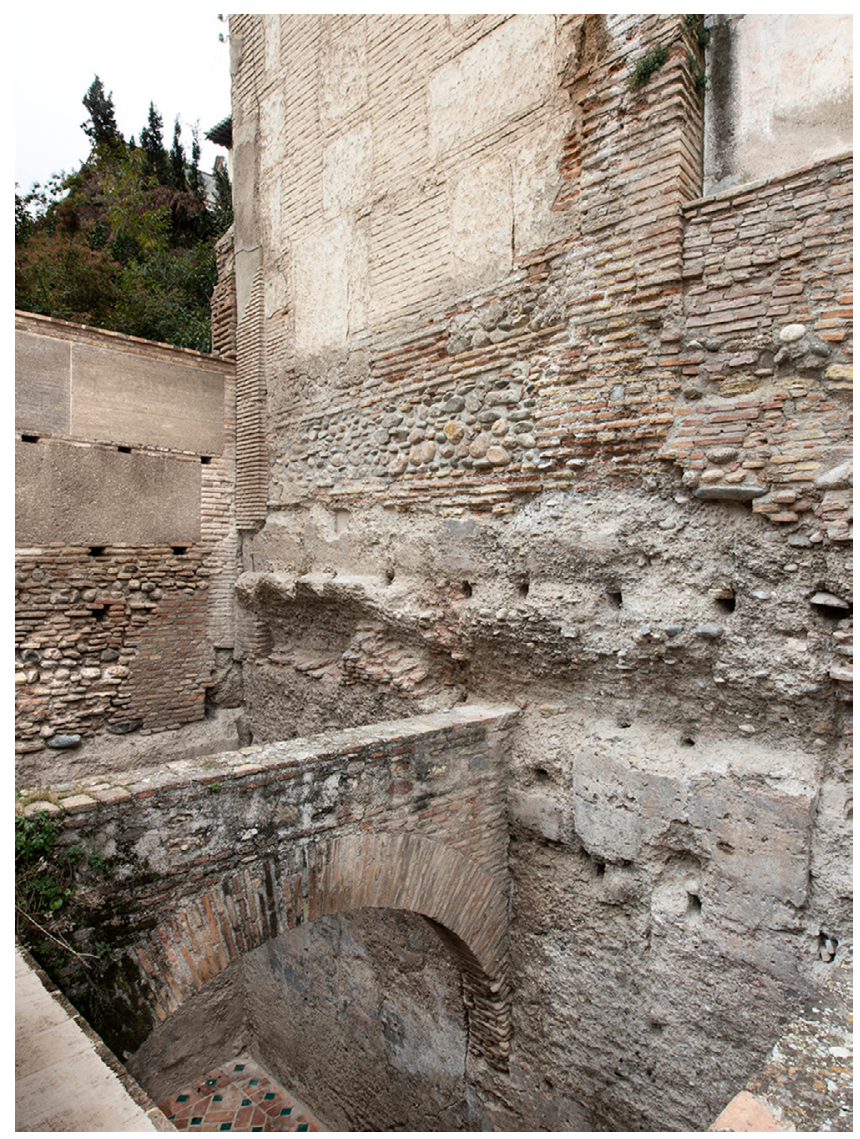

Figura 12: Vista superior de sala de servicio. Foto: C. García Zarza.

de paramentos y en consolidaciones superficiales, atendiendo especialmente a los contactos entre los estratos. En el frente norte se realizaron consolidaciones de la tapia de hormigón y de las fábricas de ladrillo medievales del arranque de los arcos de la bóveda y de la rosca de ladrillo que la conforma (Figura 12). En el oeste se reintegró, además, un muro de tapia de tierra contemporáneo según la técnica del vertido y apisonado, realizando el trabajo de forma experimental y proponiendo distintas técnicas para el acabado de paramentos. Finalmente, en el este, se interviene en una fábrica mixta de época moderna. Los trabajos han permitido identificar lagunas de intervención de las obras de Torres Balbás y Prieto-Moreno, así como parcheos y recalces de época indeterminada. Se han documentado improntas en las fábricas históricas que ayudan a interpretar la estructura funcional del baño. Todo ello se recoge en un Documento Final de Obra con ortofotografías del estado previo y final de los paramentos.

\section{CONCLUSIONES}

El análisis historiográfico y estudio crítico de las doce intervenciones de restauración realizadas en el Bañuelo en los últimos noventa años, nos ha permitido disponer de valiosa información para proponer recomendaciones que podrían tenerse en cuenta en futuras actuaciones. En términos generales, los trabajos realizados en los últimos años garantizan la estabilidad estructural del edificio. No obstante, consideramos que los paramentos interiores y exteriores del baño necesitan una actuación integral de limpieza, consolidación y protección que facilite su lectura estratigráfica, tanto de los niveles medievales y modernos como de las restauraciones contemporáneas, especialmente las reconstrucciones de bóvedas y muros realizadas por Torres Balbás. Otro de los 
ámbitos que requiere una intervención integral es el tratamiento exterior de las bóvedas, pues en 2017 se realizó un tratamiento provisional mediante pintura impermeabilizante, que evita la entrada de agua pero no resuelve definitivamente el problema. Habrá que considerar la solución final más adecuada y definir el sistema de protección de las lucernas mediante elementos de cierre que impidan la penetración del agua y garanticen la correcta iluminación y ventilación interior.

Aparte de estas actuaciones que consideramos necesarias para la correcta conservación e interpretación del monumento, presentamos, a continuación, una serie de recomendaciones de carácter más subjetivo, que podrían tenerse en cuenta en la planificación de las futuras restauraciones, y que describimos según cuatro ámbitos de actuación: a) Patio actual de entrada; b) Patio trasero o sala de servicio; c) Sala caliente; y d) Escaleras originales y relación con otras dependencias.

El actual patio de entrada es uno de los espacios más transformados, ya que fue sala de reposo del baño, que debió de cubrirse con armadura a cuatro aguas y linterna. En la actualidad, la simetría de la planta está alterada por el muro moderno de la crujía del Darro y por la galería cerrada construida en 1983. Estas estructuras ahora no cumplen ninguna función, invadiendo el espacio central y dificultando su correcta interpretación. Por otro lado, en el ángulo suroeste del patio hay una escalera de dos tramos con terraza que levantó Torres Balbás para acceder a las cubiertas y a la planta alta de la vivienda, elemento de posible necesidad funcional pero de dudosa configuración arquitectónica. Así mismo, en 2017, la planta baja sufre nuevas transformaciones, instalándose un aseo de personal y otras dependencias. El resultado es una secuencia desordenada de espacios y volúmenes, generada por las distintas intervenciones realizadas según las demandas funcionales de cada época. El sector exige, por tanto, una actuación global que se adapte a las necesidades reales del edificio, y que no podrá ser definida sin un completo estudio arqueológico y arquitectónico que establezca una valoración crítica de la actual espacialidad en relación a los estratos murarios originales.

El segundo de los ámbitos que requieren una profunda reflexión se sitúa en el otro extremo del baño, en la sala de servicio y su conexión con los espacios interiores. Torres Balbás consideró, en su proyecto de 1927, que no era urgente rehacer la bóveda que cubría esta sala. Sin embargo, a pesar de las intervenciones realizadas, la zona se encuentra permanente afectada por humedades y resulta uno de los ámbitos de mayor riesgo estructural, debido a la importante altura del muro de la casa colindante que apoya en la fábrica del baño, en su frente norte (Figura 12). En la actualidad, podría plantearse la reconstrucción documentada de la bóveda, pues existen improntas evidentes y restos del arranque de la rosca de ladrillo que la conformaba. Por otra parte, el pavimento con olambrillas instalado en 1994-95 es inapropiado para la zona de servicios y, además, elevó el nivel unos $15 \mathrm{~cm}$, ocultando parcialmente el primer peldaño de la escalera original de subida a cubierta, por lo que sería adecuado sustituirlo por otro más apropiado (Figura 13).

El tercer ámbito del análisis, la sala caliente, está separado de la de servicio por la estancia de la caldera, que se presenta ahora conectada visualmente con la sala caliente median-

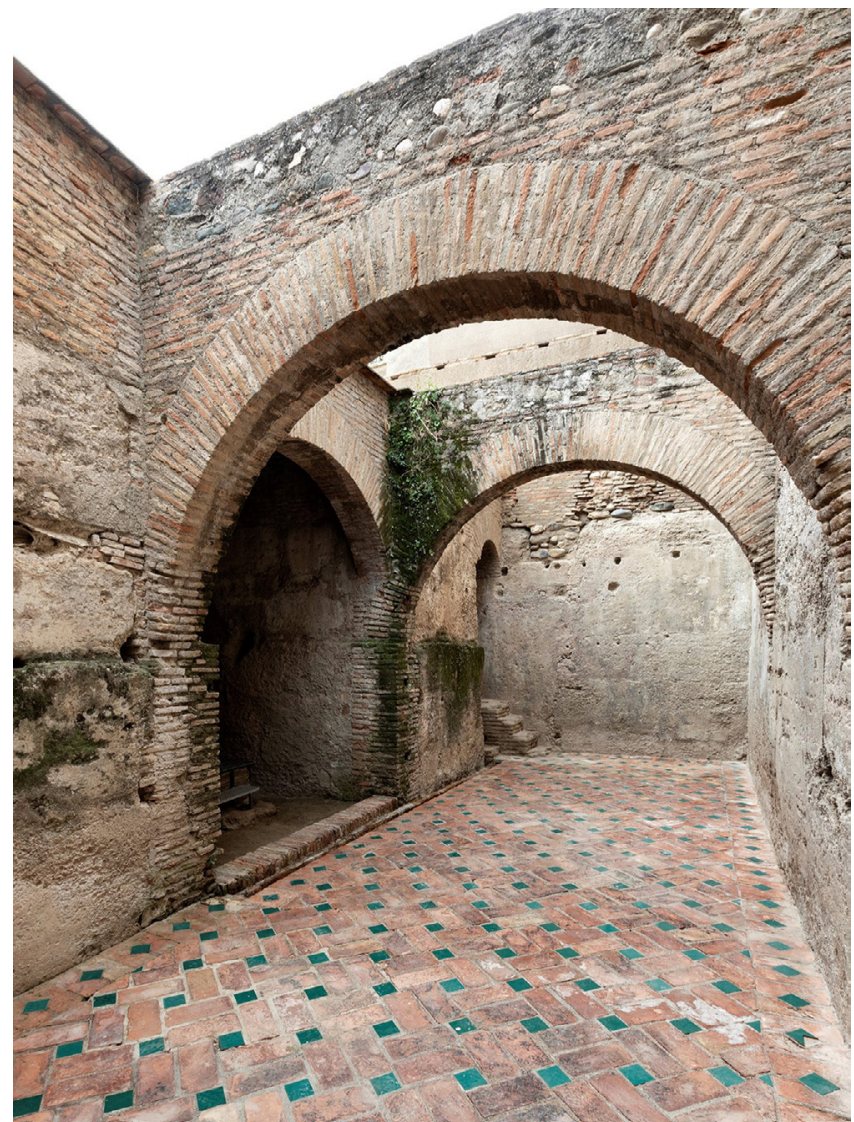

Figura 13: Vista de la sala de servicio. Al fondo, escalera medieval para subir a cubierta. Foto: Cristina García Zarza.

te una reja metálica. Sin embargo, es conocido que, en los baños andalusíes, ambos espacios estaban separados por un tabique de ladrillo que impedía vistas directas pero permitía el paso del calor, como se ha conservado en el baño del Palacio de Comares de la Alhambra. El espacio se representa en la actualidad de forma confusa, pues el visitante percibe la entrada de luz procedente de la sala de servicio, convertida ahora en patio trasero (Figura 13), estableciendo una relación visual con la zona de la caldera, inexistente en época medieval. La posible recuperación de la bóveda de la antigua leñera y un tratamiento parcialmente cerrado de este elemento de separación, podrían alterar la percepción del espacio actual, pero contribuirían, sin duda, a una mejor comprensión de uno de los ámbitos más característicos del baño andalusí. Por otro lado, ya en el interior de la sala caliente, en 1994-95 se hicieron también trabajos de restauración en la alhanía oeste, reponiendo, con buen criterio, dos columnas semiempotradas de piedra que, como se ha mencionado, fueron retiradas con posterioridad y sustituidas por pilastras de ladrillo (Figura 10). En este sentido, consideramos que podría revertirse esta actuación, recuperando las columnas semiempotradas que debieron de existir en esta sala, como manifiestan las improntas en los muros y los registros planimétricos (Figura 5).

El último de los ámbitos está relacionado con la localización de las escaleras originales del baño y su relación funcional con otras dependencias. La primera de estas escaleras fue vista o dibujada, en el sector sur, por Contreras en 1878 (7), y debía de permitir la subida a la cubierta. En este lugar, Torres Balbás construyó una escalera de dos tramos, que también subía a la planta alta de la vivienda. Otra escalera para acceder a cubierta es la situada en el frente occidental 
de la sala de servicio, de la que se conservan cuatro escalones medievales que fueron recogidos en croquis y planos de Torres Balbás (Figura 5), apareciendo también en el plano de 1951 de Gómez-Moreno Martínez. En los trabajos de limpieza realizados en 2015-18, aparecieron improntas de esta escalera, con incisiones del trazado y replanteo de su bóveda, así como restos de mortero de los peldaños. La localización de esta escalera parece documentada y funcionalmente acertada, por lo que sería posible su restitución, sustituyendo la ejecutada durante la intervención de 1994-95 en el frente opuesto. No obstante, para recuperar la escalera medieval habría que eliminar la pequeña bóveda de cañón que levantó Torres Balbás en este espacio. Finalmente, nos referiremos a otra de las escaleras necesarias para compren- der la funcionalidad del baño, la que permitiría la conexión de la leñera con la actual calle Bañuelo. Se trata de la identificada en el sector oriental de este espacio, de la que solo se conserva un escalón y algunas improntas de su desarrollo, identificadas en los trabajos de 2015-18, en el muro de hormigón del frente norte. La escalera ocuparía parte de la parcela de $18 \mathrm{~m}^{2}$ que Torres Balbás recogió en su plano de 15.09.1927 (APAG P-001829), planteando su expropiación. Ahora, este ámbito está integrado en una parcela catastral con entrada principal por la calle Carnero $\mathrm{n}^{\circ} 8$. Al no existir edificaciones importantes en el sector, es probable que una excavación arqueológica pudiese encontrar vestigios del acceso medieval o de posibles restos de un aljibe de almacenamiento de agua para el baño, que pudo existir en la zona.

\section{REFERENCIAS / REFERENCES}

(1) Gómez-Moreno [González], M. (1892). Guía de Granada, pp. 415-418, Granada: Imprenta I. Ventura ( $2^{\text {a }}$ Ed. facsímil, Universidad de Granada-Instituto Gómez-Moreno, II vol., 1982).

(2) Gómez-Moreno González, M. (1901). El Bañuelo. En Moya-Morales, J., Manuel Gómez-Moreno González. Obra dispersa e inédita, Compilación y Estudio Preliminar (p. 636). Granada: Instituto Gómez-Moreno Fundación Rodríguez-Acosta, 2004.

(3) López Guzmán, R. (2007). La arquitectura doméstica granadina en los inicios del siglo XVI. En Passini, J. e Izquierdo Benito, R. (Coord.), La Ciudad medieval de Toledo: Historia, arqueología y rehabilitación de la casa (pp. 17-34). Toledo: Universidad de Castilla-La Mancha.

(4) Orihuela, A. y López-Osorio, J.M. (2019). Knowledge and interpretation processes of the andalusí Bath of el Nogal or Bañuelo (ḥammām al-yawza) in Granada, Spain (1832-2019). WIT Transactions on The Built Environment, 191: 97111. http://dx.doi.org/10.2495/STR190091.

(5) Girault de Prangey, J.-Ph. (1837). Monuments Arabes et Moresques de Cordoue, Seville et Grenade. Souvenirs de Grenade et de l'Alhambra, Paris: Chez Veith et Hauser ( $1^{\text {a }}$ edición en castellano, Recuerdos de Granada y de la Alhambra, Barcelona: Editorial Escudo de Oro, 1982).

(6) Véase n. 2.

(7) Contreras, R. (1878). Estudio descriptivo de los monumentos árabes de Granada, Sevilla y Córdoba, pp. 348-349, 2a ed., Madrid: Imprenta Litografía de A. Rodero.

(8) Gómez-Moreno Martínez, M. (1889). Boletín del Centro Artístico de Granada. Sección de Excursiones, 74: 9, 16/10/1889.

(9) Véase n. 1.

(10) Pozo Felguera, G. (2018). Los hombres que salvaron el Bañuelo milenario. El Independiente de Granada, 18/11/2018. http://www.elindependientedegranada.es/cultura/hombres-que-salvaron-banuelo-milenario\#disqus_thread.

(11) Archivo Municipal de Granada, Leg. 2283, pieza 30. Negociado de Fomento, 1912 (8 de noviembre), exp. 36. Incoado a instancia de Gonzalo Enríquez de Luna y Enríquez solicitando autorización para desescombrar un baño árabe enterrado en la casa ${ }^{0} 37$ de la Carrera de Darro.

(12) Torres Balbás, L. (1928). Los monumentos de Granada en 1928. Revista Reflejos, abril, pp. 57-59.

(13) Gómez-Moreno [Martínez], M. (1951). Ars Hispaniae. Historia universal del arte hispánico. Vol. III: El arte árabe español hasta los almohades. Arte mozárabe / por Manuel Gómez-Moreno, pp. 257-261, Madrid: Editorial Plus-Ultra.

(14) Navarro Palazón, J. y Jiménez Castillo, P. (2012). El Bañuelo de Granada en su contexto arquitectónico y urbanístico. El legado andalusí, 45: 1-9.

(15) Almagro Gorbea, A. (2004). Levantamiento arquitectónico (pp. 111-116). Granada: Universidad de Granada.

(16) Almagro [Gorbea], A. (2014). Una hipótesis sobre la forma original del Bañuelo de Granada. En Sánchez-Mesa, D, López-Guadalupe, J.J (Eds.), Diálogos de Arte. Homenaje al profesor Domingo Sánchez-Mesa Martín (pp. 89-94). Granada: Editorial Universidad de Granada.

(17) Vílchez Vílchez, C. (2019). Baños andalusíes en Granada. En Pozuelo, C., Cortés, I. (Eds.) Los baños en al-Andalus (pp. 154-167). Granada: Fundación Pública Andaluza El legado andalusí.

(18) Torres Balbás, L. (1931). Los monumentos árabes de Granada. Obras recientes y adquisiciones Arquitectura, enero, 1931. Reeditado en Torres Balbás, L, Sobre Monumentos y otros escritos (pp. 251-260). Madrid: COAM, 1996.

(19) Véase n. 16.

(20) Véase n. 5 .

(21) Henríquez de Jorquera, F. (1987). Anales de Granada. Estudio preliminar e índices por Pedro Gan Giménez y Luis Moreno Garzón (p. 561). Granada: Universidad de Granada.

(22) Memoria 2014 del Conjunto Monumental de la Alhambra y Generalife. PAG, Apartados: 4.3.14, p. 147; 4.3.16, 4.3.17, p. 148.

(23) Memoria 2015 del Conjunto Monumental de la Alhambra y Generalife. PAG, Apartado 5.4.8, p. 166.

(24) Memoria 2017 del Conjunto Monumental de la Alhambra y Generalife. PAG, Apartado 5.5.9, p. 186. 